\title{
Pathogenesis of hypogammaglobulinaemia with thymoma and late-onset hypogammaglobulinaemia
}

\author{
G. L. ASHERSON, SHEENA JOHNSON, T. A. E. PLATTS-Mills, \\ AND A. D. B. WEBSTER \\ From the Immune Deficiency Referral Laboratory and the Division of Immunological Medicine, \\ Clinical Research Centre, Harrow, England
}

Clinical observation over the past 10 years has revealed some of the causes of hypogammaglobulinaemia. Purtilo et al. (1977) observed the sex-linked, recessive lymphoproliferative syndrome (Duncan's disease) in which infectious mononucleosis may cause persistent hypogammaglobulinaemia affecting IgG, IgM, and IgA. Sorrell et al. (1971) noted selective diminution of serum IgA in patients treated with phenytoin (Epanutin). This drug rarely may cause hypogammaglobulinaemia affecting IgG, IgM, and IgA (de Gast et al., 1974). There is now an animal model for this phenomenon (Seagar et al., 1978). Other drugs used in the treatment of epilepsy and gold and penicillamine also may cause selective diminution of serum IgA (Stanworth et al., 1977).

There have been two important conceptual advances during the decade. Interest in the development of $B$ cells in the bone marrow has led to the concept that hypogammaglobulinaemia may be due to an arrest of $B$ cell development at an immature stage or to death of $B$ cells beyond a particular stage. The ability to recognise B cells by their surface immunoglobulin has led to the realisation that nearly all patients with sex-linked hypogammaglobulinaemia have very few B cells in their peripheral blood. This is also true for most patients with hypogammaglobulinaemia due to thymoma and a minority of patients with late-onset hypogammaglobulinaemia.

These observations have focused attention on factors that might limit B cell production in the bone marrow. The finding that some patients with lateonset hypogammaglobulinaemia have normal or low normal numbers of $\mathbf{B}$ cells in the peripheral blood has led to experiments to determine whether these B cells are functionally normal but fail to produce immunoglobulin because of a suppressor cell, or whether they are abnormal and perhaps immature B cells.

The second important conceptual advance has arisen from the demonstration by Gershon and others of the existence of suppressor cells. These are operationally defined as cells that interfere with the immunological phenomenon under study, and it is important to realise that there are several different types of suppressor cells which affect different immune responses and have different modes of action. This concept together with the development of the pokeweed mitogen system for studying immunoglobulin production in vitro has led to the recognition of both $\mathbf{T}$ and $\mathbf{B}$ cell abnormalities in hypogammaglobulinaemia.

In principle, disease may affect $\mathbf{B}$ cell development at any stage. The earliest recognisable defect is loss of the pre-B cell, which is regarded as the precursor of $B$ cells in the bone marrow. This occurs in patients with hypogammaglobulinaemia due to thymoma (Pearl et al., 1978; Hayward, 1978). Alternatively, further development of B cells in the bone marrow may be limited. One hypothesis, which will be discussed later, is that immature B cells of the type normally found in the bone marrow occur in the peripheral blood in late-onset hypogammaglobulinaemia. In principle, failure of $B$ cell development may be due to death of cells beyond a certain stage of development. This might be caused by, for instance, infection with a virus, such as the Epstein-Barr virus, or by an autoimmune process.

Failure of B cell development caused by an inherited disease might be due to the loss of a specific receptor or inductive factor needed for some stage of B cell development. Alternatively, a generalised biochemical defect might have a selective effect on B cell development There is no example of this phenomenon for B cells, but loss of nucleoside phosphorylase, a widely distributed enzyme, selectively affects $T$ cells. It is an interesting question whether the drugs, such as phenytoin, that affect IgA production act primarily on the development of B cells.

Waldmann et al. (1974) put forward the suppressor cell hypothesis. This states, in its extreme form, that hypogammaglobulinaemia is due to suppressor $T$ 
cells which prevent immunoglobulin production and that the patients' B cells are intrinsically normal. An alternative view is that abnormal $\mathrm{T}$ cells may inhibit the development of B cells in the bone marrow. The latter receives indirect support from the finding of $T$ cells which limit red cell development in patients with aplastic anaemia. However, the interpretation of these studies is complicated because the same effect can be produced by blood transfusions which immunise against foreign bone marrow cells (Singer et al., 1978). This theoretical discussion provides a background for the consideration of hypogammaglobulinaemia due to thymoma and late-onset hypogammaglobulinaemia. The American literature is summarised in Waldmann et al. (1978) and Siegal et al. (1978).

\section{Thymoma}

Good and Varco (1955) described the association of thymoma and hypogammaglobulinaemia. The initial view was that the thymoma was the result and not the cause of the hypogammaglobulinaemia. This view now seems unlikely and thymoma should be regarded as one of the causes of hypogammaglobulinaemia. The best evidence for this is that thymoma is never seen in patients with sex-linked hypogammaglobulinaemia and does not develop in patients with established late-onset hypogammaglobulinaemia. Moreover, the thymoma is associated with a particular type of hypogammaglobulinaemia in which cell-mediated immunity is usually intact, B cells are absent from the peripheral blood, and there is no splenomegaly.

There are several interesting features of hypogammaglobulinaemia caused by thymoma. (1) The thymoma always contains epithelial elements and is not a pure lymphoid tumour. (2) B cells are very low or absent from the pcripheral blood and pre-B cells absent from the bone marrow. (3) Other complications of thymoma are common, in particular pure red cell aplasia, neutropenia, and thrombocytopenia. (4) In one patient (V.Y.) antibodies to lymphocytes active at $37^{\circ} \mathrm{C}$ were found during a period of extreme leucopenia. (5) $\mathrm{T}$ suppressor cells which inhibit immunoglobulin production occur in the peripheral blood (Litwin and Zanjani, 1977).

Studies of suppressor cells in hypogammaglobulinaemia are based on the ability of pokeweed mitogen to stimulate B cells to produce immunoglobulin in vitro. This immunoglobulin production can be quantitatively measured by radioimmunoassay and is dependent on the presence of $T$ cells. These $T$ cells may be autologous or come from another subject, and mitomycin-treated $\mathrm{T}$ cells are active. Immunoglobulin production depends on the
$\mathrm{T}$ to $\mathrm{B}$ ratio. An excessively high ratio of $\mathrm{T}$ cell to B cells decreases immunoglobulin production. This is a normal phenomenon and occurs both in healthy subjects and in patients with late-onset hypogammaglobulinaemia (Janossy et al., 1977; de la Concha et al., 1977). For this reason pathological suppression cannot be demonstrated without careful attention to the $T$ to $B$ ratio. Recently suppression has been studied by adding a small number of the patient's $T$ cells to a mixture of normal $B$ cells and normal mitomycin-treated $T$ cells. Table 1 shows that the $T$ cells of a patient with thymoma caused severe depression of immunoglobulin production (de Gast et al., 1979a).

\section{Table 1 Suppressor $T$ cells in patients with thymoma*}

Normal T + normal B

Normal T + normal B + normal Tmito

Normal T + normal B + thymoma Tmito

Normal $T+$ normal $B+$ normal $T$

Normal T + normal B + thymoma T

*'Positively' purified (see text) normal B cells $\left(1.25 \times 10^{5}\right)$ were mixed with allogeneic, mitomycin-treated $\mathrm{T}$ cells. These were then stimulated by pokeweed mitogen and IgM measured seven days later in $\mu \mathrm{g} / \mathrm{ml}$. To assess suppressor cells equal numbers $\left(6 \times 10^{4}\right)$ of normal $T$ cells or T cells from a patient with thymoma were added. The data show that the patient's $T$ cells, whether treated (Tmito) or untreated (T) with mitomycin $C$, suppressed immunoglobulin production while normal $\mathrm{T}$ cells caused an increase. This experiment was repeated with similar results (de Gast et al., 1979a).

Any account of the pathogenesis of hypogammaglobulinaemia caused by thymoma must explain why B cells are virtually absent from the peripheral blood. It is not yet known whether the suppressor $\mathrm{T}$ cells, which are detected by their ability to block immunoglobulin production in vitro, also kill B cells or prevent their normal development in the bone marrow. Our working hypothesis is that the various diseases associated with thymoma, such as pure red cell aplasia, pancytopenia, myasthenia gravis, systemic lupus erythematosus, and pemphigus, as well as hypogammaglobulinaemia are due to an autoimmune process. The only evidence for this, however, is the association of thymoma with putative autoimmune diseases (Souadjain et al., 1974).

\section{Late-onset hypogammaglobulinaemia}

The term 'common variable immunodeficiency' is confusing (Gatti, 1974). It describes any patient with impairment of both humoral and cellular immunity who cannot be classified as severe combined immunodeficiency because of prolonged survival (Fudenberg et al., 1971). This includes children with severe $\mathrm{T}$ cell defects who have clinical manifestations 
such as oral candidiasis, severe chickenpox, or Pneumocystis carinii pneumonia. It also includes adults with hypogammaglobulinaemia, affecting IgG and IgA, and usually IgM, with depressed cell-mediated immunity. For this reason it is helpful to separate a group of patients under the heading of late-onset hypogammaglobulinaemia.

The term 'late-onset hypogammaglobulinaemia' is used here to describe patients with the following features. (1) The occurrence of hypogammaglobulinaemia affecting $\operatorname{IgG}, \operatorname{IgA}$, and usually IgM which is not due to sex-linked hypogammaglobulinaemia, thymoma, or other recognised cause. (2) Presentation after the second birthday. This excludes most cases of sex-linked hypogammaglobulinaemia in which the diagnosis cannot be established because of the lack of a family history. (3) Normal percentage of T cells by $\mathrm{E}$ rosetting. This distinguishes the condition from the rare children with severe $T$ cell defects who develop characteristic infections such as oral candidiasis, Pneumocystis carinii pneumonia, or severe vaccinia and varicella. Nevertheless, about one-third of patients with late-onset hypogammaglobulinaemia have depressed $\mathrm{T}$ cell function as shown by delayed and contact hypersensitivity skin tests and blast transformation to phytohaemagglutinin. They do not suffer, however, from the infections characteristic of severe $T$ cell deficiency.

Both $B$ and $T$ cells function may be altered in lateonset hypogammaglobulinaemia. B cells are low in about one-third of patients (Horwitz et al., 1977). de la Concha et al. (1977) purified B cells 'negatively' by removing $T$ cells and studied them in a pokeweed mitogen system. The B cells of patients with hypogammaglobulinaemia were defective and failed to produce normal amounts of immunoglobulin even when removed from their own $\mathrm{T}$ cells and provided with normal $T$ cell help. Recently de Gast et al. (1979b) purified B cells 'positively' by their ability to adhere to ox red cells coated with anti-IgM. These positively purified B cells showed defective immunoglobulin production in the seven patients studied (Table 2). This provides formal proof that there is a consistent B cell defect in late-onset hypogammaglobulinaemia and that the observations are not an artifact due to inappropriate $\mathrm{T}$ to $\mathrm{B}$ cell ratios or to contamination of the patient's B cells with $T$ cells that might have a suppressor effect.

de Gast et al. (1979c, d) studied a population of bone marrow $B$ cells obtained from ribs removed at thoracotomy, and compared them with the peripheral blood $\mathrm{B}$ cells of normal individuals. The bone marrow B cells were inferior in their ability to make immunoglobulin, to stimulate in the mixed lymphocyte reaction, and to divide when provided with $T$ cell help from mitomycin-treated $\mathrm{T}$ cells.
Table 2 Mean production of immunoglobulin by purified $B$ cells from patients with late-onset hypogammaglobulinaemia and from normal control subjects*

\begin{tabular}{lllll}
\hline & Controls & Patients & $P / C \%$ & $<0.05 \mu \mathrm{g} / \mathrm{ml}$ \\
\hline IgM & 5.5 & 0.35 & $64 \%$ & $2 / 7$ \\
IgG & 2.0 & 0.06 & $3 \%$ & $5 / 7$ \\
IgA & 0.51 & 0.07 & - & $6 / 7$ \\
\hline
\end{tabular}

*The figures show the mean production of IgM, IgG, and IgA in $\mu \mathrm{g} / \mathrm{ml}$ seven days after stimulation with pokeweed mitogen as measured by radioimmunoassay. $\mathrm{P} / \mathrm{C} \%$ indicates the $\mathrm{Ig}$ production by the patients expressed as a percentage of that in the controls. The number of patients whose response was undetectable $(<0.05 \mu \mathrm{g} / \mathrm{ml})$ is also shown. All control subjects gave a detectable response. The B cells were 'positively' purified and provided with normal T cell help. Five control subjects and seven patients were studied.

Studies in hypogammaglobulinaemia show that the peripheral blood $\mathrm{B}$ cells resemble bone marrow B cells in their poor functional capacity. This is indicated schematically in Table 3 . The findings indicate that the peripheral blood in late-onset hypogammaglobulinaemia has an undue number of immature B cells of the type normally found in the bone marrow. An alternative view is that these 'immature' bone marrow B cells occur in the peripheral blood in both normal subjects and in patients with hypogammaglobulinaemia but that a mature population is absent from the peripheral blood in late-onset hypogammaglobulinaemia.

Table 3 Functional activities of normal peripheral blood $B$ cells, normal bone marrow $B$ cells, and the blood $B$ cells in patients with late-onset hypogammaglobulinaemia*

\begin{tabular}{|c|c|c|c|}
\hline & \multicolumn{2}{|l|}{ Normal } & \multirow{2}{*}{$\begin{array}{l}\text { Hypogg } \\
\text { blood }\end{array}$} \\
\hline & Blood & $B M$ & \\
\hline IgM & $++t$ & ++ to - & ++ to - \\
\hline IgG & ++ & + to - & + to - \\
\hline IgA & ++ & - & $(+)$ to - \\
\hline PWM & ++ & + to \pm & + to \pm \\
\hline MLR & ++ & ++ to $=$ & + to - \\
\hline
\end{tabular}

*This chart compares schematically the behaviour of purified B cells from the blood and bone marrow (BM) of normal individuals and from the blood of patients with late-onset hypogammaglobulinaemia (Hypogg). The cells were provided with $T$ cell help and their IgM, IgG, and IgA synthesis measured seven days after stimulation by pokeweed mitogen. Their ability to divide when stimulated with pokeweed mitogen (PWM) and to stimulate in a mixed lymphocyte reaction (MLR) were also assessed. 6-8 subjects were studied in each group. (+) Means that only one patient gave a measurable response.

Another B cell defect seen in late-onset hypogammaglobulinaemia is the low amount of $5^{\prime}$ nucleotidase in the peripheral blood B cells. This was seen in two out of five patients studied (Rowe et al., 1979).

$\mathrm{T}$ cell defects also occur in late-onset hypogamma- 
globulinaemia but some are probably irrelevant to the pathogenesis. For instance, about one-third of patients have loss of delayed and contact sensitivity skin reactions and impaired blast transformation. Nevertheless, the percentage of cells forming $E$ rosettes is normal (Webster and Asherson, 1974). Many patients with late-onset hypogammaglobulinaemia have low $5^{\prime}$-nucleotidase in the peripheral blood mononuclear cells, and this has been confirmed by Edwards et al. (1978). This defect involves both $T$ and $B$ cells and the amount in T cells was low in 5 out of 10 patients with late-onset hypogammaglobulinaemia (Rowe et al., 1979).

What is the evidence for the occurrence of suppressor $\mathbf{T}$ cells in hypogammaglobulinaemia? In most patients the $T$ cells are normal, as judged by their ability to provide $\mathrm{T}$ cell help for immunoglobulin production when present in low numbers, and cause suppression when present at a high $\mathrm{T}$ to $\mathrm{B}$ ratio (de la Concha et al., 1977). Because of this $T$ to $B$ ratio dependency of immunoglobulin production a special system is necessary to study abnormal suppressor cells. Suppressor T cells are detected by adding a small number of the patient's $T$ cells to a mixture of normal B cells and normal, mitomycintreated T cells. Such suppressor cells were found in three patients. All of them were unusual. One had pure red cell aplasia with hypogammaglobulinaemia affecting $\operatorname{IgM}, \operatorname{IgA}$, and to a lesser extent IgG; another had autoimmune haemolytic anaemia; and the third had ulcerative colitis. Two of these patients had very few B cells.

What conclusions may be drawn? Clearly both $T$ and $B$ cells are altered in many patients with lateonset hypogammaglobulinaemia. It is unlikely that the $T$ cell defect is secondary to the $B$ cell defect since similar changes, with the possible exception of 5 '-nucleotidase, do not occur in sex-linked hypogammaglobulinaemia. Clearly also suppressor cells of the type envisaged by Waldmann which prevent normal B cells from producing immunoglobulin cannot be important in the pathogenesis in most patients. That is because suppressor cells can be demonstrated only in a minority of patients and because the consistent defect is the inability of B cells to function even when provided with normal $T$ cells. Moreover, some patients have few or no B cells.

Nevertheless, there is another way in which $T$ cells might affect $\mathrm{B}$ cells, and this is by an autoimmune or suppressor effect on their development in the bone marrow. This possibility merits further study.

\section{Conclusions}

(1) Thymoma is a cause and not the result of hypogammaglobulinaemia. The main evidence is that thymoma does not occur in patients with sexlinked or established late-onset hypogammaglobulinaemia.

(2) The hypogammaglobulinaemia caused by thymoma is probably due to an autoimmune process. The evidence for this is the occurrence of a number of putative autoimmune diseases in patients with thymoma.

(3) The percentage of $\mathbf{B}$ cells in the peripheral blood is very low in our two patients with hypogammaglobulinaemia caused by thymoma and in similar patients described in the literature.

(4) The production of immunoglobulin by B cells stimulated by pokeweed mitogen depends on the $T$ to $B$ cell ratio. Low numbers of $T$ cells are required to provide $\mathrm{T}$ cell help, but a high ratio of $\mathrm{T}$ to $\mathrm{B}$ cells causes suppression. This is a normal phenomenon. However, two patients with thymoma had $T$ suppressor cells that caused suppression when added in small numbers to a mixture of $T$ and $B$ cells which alone showed good immunoglobulin production. It is an important question whether these or other suppressor cells explain the low numbers of B cells in the peripheral blood.

(5) In late-onset hypogammaglobulinaemia there is a consistent B cell defect and B cells, which have been highly purified by virtue of their surface immunoglobulin, have a severe impairment of immunoglobulin production even when providedo with normal $T$ cell help. A population of bone marrow B cells from subjects without hypogammaglobulinaemia shows the same feature. It is proposed that the B cells in the peripheral blood of patients with late-onset hypogammaglobulinaemia may be identical to normal 'immature' bone marrow B cells.

(6) The T cells of most patients with late-onset hypogammaglobulinaemia are identical with those of normal subjects, providing help at low $\mathrm{T}$ to $\mathrm{B}$ cell ratios and suppression at higher ratios. Suppressor cells, however, were found in three unusual patients.

\section{References}

de Gast, G. C., The, T. H., Viersma, J. W., Marrink, J., and Arisz, L. A. (1974). Reversible hypogammaglobulinaemia after diphenylhydantoin and hydroxyzine therapy. Netherlands Journal of Medicine, 17, 261-269. de Gast, G. C., et al. (1979a). In preparation.

de Gast, G. C., et al. (1979b). In preparation.

de Gast, G. C., and Platts-Mills, T. A. E. (1979c). Functional studies on lymphocytes in adult human bone marrow. I. Immunoglobulin production in vitro after fractionation on a sucrose gradient and $T /$ non- $T$ cell separation. Journal of Immunology, 122, 280-284.

de Gast, G. C., and Platts-Mills, T. A. E. (1979d). Functional studies on lymphocytes in adult human 
bone marrow. II. Isolated surface IgM-positive cells. Journal of Immunology, 122, 285-290.

de la Concha, E. G., Oldham, G., Webster, A. D. B., Asherson, G. L., and Platts-Mills, T. A. E. (1977). Quantitative measurements of T- and B-cell function in 'variable' primary hypogammaglobulinaemia: evidence for a consistent B-cell defect. Clinical and Experimental Immunology, 27, 208-215.

Edwards, N. L., Magilavy, D. B., Cassidy, J. T., and Fox, 1. H. (1978). Lymphocyte ecto-5'-nucleotidase deficiency in agammaglobulinemia. Science, 201, 628-630.

Gatti, R. A. (1974). On the classification of patients with primary immunodeficiency disorders. Clinical Immunology and Immunopathology, 3, 243-247.

Good, R. A., and Varco, R. L. (1955). A clinical and experimental study of agammaglobulinaemia. JournalLancet, 75, 245-271.

Hayward, A. R. (1978). Hypogammaglobulinaemia with deficiency of pre-B cells. Lancet, 1, 1014-1015.

Horwitz, D. A., Webster, A. D. B., and Newton, C. (1977). B and L lymphocytes in primary hypogammaglobulinaemia. Lancet, 2, 823-824.

Janossy, G., de la Concha, E. G., Luquetti, A., Snajdr, M. J., Waxdal, M. J., and Platts-Mills, T. A. E. (1977). $T$ cell regulation of immunoglobulin synthesis and proliferation in pokeweed (Pa-1) stimulated human lymphocyte cultures. Scandinavian Journal of Immunology, 6, 109-123.

Litwin, S. D., and Zanjani, E. D. (1977). Lymphocytes suppressing both immunoglobulin production and erythroid differentiation in hypogammaglobulinaemia. Nature (London), 266, 57-58.

Pearl, E. R., Vogler, L. B., Okos, A. J., Crist, W. M., Lawton, A. R., and Cooper, M. D. (1978). B lymphocyte precursors in human bone marrow: an analysis of normal individuals and patients with antibodydeficiency states. Journal of Immunology, 120, 11691175.

Purtilo, D. T., DeFlorio, D., Jr., Hutt, L. M., Bhawan, J., Yang, J. P. S., Otto, R., and Edwards, W. (1977). Variable phenotypic expression of an X-linked recessive lymphoproliferative syndrome. New England Journal of Medicine, 297, 1077-1081.

Rowe, M., de Gast, G. C., Platts-Mills, T. A. E., Asherson, G. L., Webster, A. D. B., and Johnson,
S. M. (1979). Lymphocyte 5'-nucleotidase deficiency in primary hypogammaglobulinaemia and cord blood. Clinical and Experimental Immunology. In press.

Seager, J., Coovadia, H. M., and Soothill, J. F. (1978). Reduced immunoglobulin concentration and impaired macrophage function in mice due to diphenylhydantoin. Clinical and Experimental Immunology, 33, 437-440.

Siegal, F. P., Siegal, M., and Good, R. A. (1978). Role of helper, suppressor and B-cell defects in the pathogenesis of the hypogammaglobulinemias. New England Journal of Medicine, 299, 172-178.

Singer, J. W., Brown, J. E., James, M. C., Dorey, K., Warren, R. P., Storb, R., and Thomas, E. D. (1978). Effect of peripheral blood lymphocytes from patients with aplastic anemia on granulocytic colony growth from HLA-matched and mismatched marrows: effect of transfusion sensitization. Blood, 52, 37-46.

Sorrell, T. C., Forbes, I. J., Burness, F. R., and Rischbieth, R. H. C. (1971). Depression of immunological function in patients treated with phenytoin (sodium diphenylhydantoin). Lancet, 2, 1233-1235.

Souadjian, J. V., Enriquez, P., Silverstein, M. N., and Pépin, J. M. (1974). The spectrum of diseases associated with thymoma: coincidence or syndrome. Archives of Internal Medicine, 134, 374-379.

Stanworth, D. R., Johns, P., Williamson, N., Shadforth, M., Felix-Davies, D., and Thompson, R. (1977). Drug induced IgA deficiency in rheumatoid arthritis. Lancet, 1, 1001-1002.

Waldmann, T. A., Blaese, R. M., Broder, S., Krakauer, R. S. (1978). Disorders of suppressor immunoregulatory cells in the pathogenesis of immunodeficiency and autoimmunity. Annals of Internal Medicine, 88, 226-238.

Waldmann, T. A., Durm, M., Broder, S., Blackman, M., Blaese, R. M., and Strober, W. (1974). The role of suppressor $\mathrm{T}$ cells in pathogenesis of common variable hypogammaglobulinaemia. Lancet, 2, 609-613.

Webster, A. D. B., and Asherson, G. L. (1974). Identification and function of $T$ cells in the peripheral blood of patients with hypogammaglobulinaemia. Clinical and Experimental Immunology, 18, 499-504.

World Health Organization (1971). Primary immunodeficiencies. Report of a World Health Organization Committee. Pediatrics, 47, 927-946. 